\title{
A Review of Workaholism and Prospects
}

\author{
Lin $\mathrm{Hu}$ \\ School of Management, Jinan University, Guangzhou, China \\ Email: 15521501985@163.com
}

How to cite this paper: $\mathrm{Hu}, \mathrm{L}$. (2018) A Review of Workaholism and Prospects. Open Journal of Social Sciences, 6, 318-334. https://doi.org/10.4236/jss.2018.611024

Received: October 29, 2018

Accepted: November 27, 2018

Published: November 30, 2018

Copyright (C 2018 by author and Scientific Research Publishing Inc. This work is licensed under the Creative Commons Attribution International License (CC BY 4.0).

http://creativecommons.org/licenses/by/4.0/

\begin{abstract}
As a kind of working group and organization situation in the background of today's age, workaholism has become a research topic which scholars have paid more and more attention to. It is of great theoretical and practical significance to carry out the study of workaholism in organizational behavior and human resource management, which not only allows managers to better adapt to the current organizational situation to improve management efficiency, but also broadens the research perspective of employee motivation. At present, the research on workaholism has not yet formed a perfect research system. Foreign research focuses on the outcome variables and mechanism of workaholism, while domestic research stays at the initial phase in this field. Accordingly, based on a systematic review of foreign literature, this paper introduces the concept and measurement of workaholism, and systematically sorts out the antecedents and outcomes of workaholism, ultimately in the hope of providing a prospect of future research about workaholism. At the same time, on this basis build a comprehensive intervention system of workaholism, thus providing practical guidance on intervention to work addiction phenomenon.
\end{abstract}

\section{Keywords}

Workaholism, Work Characteristic, Personality Characteristic, Interventions

\section{Introduction}

Since Oates coined the daily concept of workaholic as an academic topic [1], workaholics have gradually become the research topic of concern to organizational behaviorists. Workaholism refers to individuals who invest a lot of time and energy into their work [2] [3] [4], their behavior or symptoms are called "work addiction" in academia. A survey by Andreassen found that the prevalence of workaholics in Norway reached 8.3\% [5]. A survey in Italy showed that $7.6 \%$ of adolescents [6] and 10\% of American adults have work addiction [7]. 
"The China Labor Statistical Yearbook" shows that the average weekly working hours of urban employees in China is 46.1 hours. The number of people working more than 40 hours per week accounts for $49.9 \%$ of the total number, and the number of people over 48 hours accounts for $31.5 \%$. In the lodging and catering industry with the longest working hours per week who has an average working time of more than 48 hours accounting for $48.4 \%$ of the total. Although the proportion of these data is already high, it is likely to grow further [8]. The global increase in the number of workaholics may be due to changes in the labor market (such as global competition) [9], advances in science and technology have led to a diversification of modern work patterns, the blurring boundaries of work and life and other social changes [8] [10] [11]. Workaholics have become a social phenomenon and social problem, so it is of great practical significance to conduct in-depth discussion and research on workaholics.

At present, workaholic research is still in its infancy, Scholars have studied the concept, dimensions, antecedents and outcome variables of workaholics [12] [13], but there are still several important issues that need to be clarified: First, conceptually, the connotation of workaholics has not formed a unified understanding, and there is great controversy in the cognition and emotion of workaholics [2] [14], thus hindering the development of workaholic theory and empirical research [12]; Second, in measurement The measurement of the existing workaholics results in different structures and low polymerization validity due to different theories based on the theory, and lack of reliable measurement tools [14]. Third, in terms of outcome variables, workaholics have mixed effects on organizations [9], and this issue needs further exploration. In addition, the current research is still lack of systematic, and the corresponding empirical research is still relatively fragmented. In view of the above problems, this paper reviews the concept and measurement of workaholics through the collation of workaholics, systematically summarizes the antecedents and outcome variables of workaholics, and builds a workaholic based on this. In addition, this paper summarizes a set of workaholic intervention systems, and finally looks into the future direction of workaholic research.

\section{Defining Workaholism}

The term workaholism was originally derived from the analogy of "alcoholism", which means that workaholics at the beginning of their presentation show similarities to material addiction behavior. Therefore, in the early days of workaholic research, scholars considered workaholics to be an addictive behavior, even treating workaholics as a pathology [15]. With the deepening of the research, the scholars' understanding of the connotation of workaholics has been continuously expanded, and more research has been paid on the motives behind the workaholic behavior and their emotional experiences. In order to present the connotation of workaholics more comprehensively, this paper will sort out the concept of workaholic from three perspectives: cognition, behavior and emotional experience. 
First, cognitive. From a cognitive perspective, workaholics are considered an uncontrolled internal forcing and intense work need [1] [16] [17] [18], this perspective reflects the intrinsic psychological process of workaholics' focus on work [12] [13]. Although researchers have recognized the cognition of workaholics, there is still considerable controversy about the degree of coercion and need for workaholics. Most scholars are more optimistic that workaholics are obsessed with work and are less compelled; some scholars believe that workaholics are more than necessary for workaholics, and even think that workaholics are an obsessive-compulsive disorder [14]. Other scholars are extremely convinced that workaholics are a deadly disease, and workaholics are studied as a pathology [15] [19]. This controversy has been discussed in previous literature, but it has not yet been fully proved. Future research can explore this issue in depth, which may be an important factor in distinguishing between workaholics and material addiction.

Second, behavioral performance. From a behavioral perspective, workaholics are defined as over-investment in work. This over-investment is reflected in both the length of work and the excessive interference of work on personal life: First, most workaholic concepts include features that workaholics work longer hours than other groups [2], such as Mosier believes that workaholics are people who work at least 50 hours a week [4]. Some people argue that workaholic behavior patterns include three aspects: individuals spend a lot of free time on their work; often think about work outside of work [3]; do more work than organizational requirements and the basic economic needs of oneself. On the other hand, workaholics can cause work to interfere excessively with personal life. For example, some people believe that workaholics will work harder than work requirements and organizational expectations, and therefore neglect life outside of work [18]. They often choose leisure activities that promote or complement work and blur the lines between work and non-work [13] [20]. In addition, even if workaholics face negative consequences of excessive work (such as marriage or health issues), this over-investment will not decrease [12] [17].

Third, emotional experience. In terms of emotional experience, workaholics tend to be accompanied by negative emotions such as anxiety and guilt during non-work hours. These negative emotions may be due to internal compulsion behind workaholic behavior [13] [16]. There are two views on the emotional experience of workaholics at work: Some scholars believe that workaholics do not enjoy their work, and have lower work pleasure [21], The workaholism Battery which developed by Spence and Robbins in 1992 clearly states that true workaholics should include high job involvement, high job drive, and low work pleasure. Aziz and Zickar argue that low work pleasure is a feature of true workaholics, but other scholars believe that true workaholics should be to enjoy and love his or her work [13] [22]. According to Sussman, workaholics don't necessarily like their work, but may be addicted to experiencing temporary pleasures (such as getting paid or signing a new work contract) [17]. 
In summary, scholars define workaholics from the perspectives of cognition [1], behavior [3], or synthesis [13]. These concepts define workaholics from different perspectives and levels. A comprehensive and accurate workaholic definition should include both cognitive and emotional experiences of work, as well as behavioral performance at work. And the three dimensions of cognition, emotion, and behavior are not separated, but are interrelated. Based on the above analysis, this paper believes that workaholics work for a long time under an uncontrollable internal drive, and they often work with negative emotions during non-working hours and frequently think about work, even if the negative consequences are beyond the reasonable requirements to overwork individual.

\section{Measurement of Workaholism}

The study of the structure and measurement of workaholics is the basis of empirical research. Since the 1980s, researchers have begun to study the structure and measurement of workaholics. In the existing scales, although some scales are widely used, due to the scholars' research on the connotation of workaholics, the understanding of their structure is inconsistent, and the content of measurement is different, resulting in scales between each other. The aggregation efficiency is not low [14]. Through literature review, we present the main representative workaholic studies as follows (Table 1).

The existing research mainly uses the method of questionnaire survey. Among the many workaholic scales currently formed in academia, the most frequently used empirical studies are the four scales listed in Table 1. According to the measurement of the workaholic, the scale can be roughly divided into two types: The first type of scale focuses on the cognition or attitude of the workaholic, such as the Workaholic Questionnaire developed by Spence and Robbins [16], it includes three sub-scales: Work Involvement, Work Drive, Work Enjoyment. The second type of scale mainly measures the behavior of workaholics. For example, Mudrack and Nauthton's workaholic behavior scale measures workaholics from the two dimensions of overwork and forced work [23], with a focus on the specific behavior of workaholics in the organization; Andreassen treats workaholics as one an addictive behavior that measures seven core factors of addiction [24].

Because the connotation of workaholics has not been unified, the background perspective research objects of researchers are different, the current research on workaholic measurement still needs to be improved: 1) The current workaholic measurement has not been fully covered the definition, mostly measures the cognition or behavior of the workaholic alone. For example, WBS measures the behavior of workaholics, while WART prefers to measure the cognitive dimension. 2) The reliability and validity of some scales have yet to be further testing [25]. Although the overall reliability and validity of some scales have been verified, the subscales are compared low. For example, the sub-scale work involvement of the Workaholism Battery proved to be of low validity [5] [26], subscale 
Table 1. Overview of particular workaholism measures.

\begin{tabular}{|c|c|c|}
\hline Researcher & Instrumen & Subscales \\
\hline Spence \& Robbins (1992) & $\begin{array}{l}\text { Workaholism Battery } \\
\text { (WorkBAT) }\end{array}$ & $\begin{array}{c}\text { Work Involvement (WI), Drive (D), } \\
\text { Work Enjoyment (WE) }\end{array}$ \\
\hline Robbins (1999) & $\begin{array}{l}\text { Dutch Work Addiction } \\
\text { Scale (DUWAS) }\end{array}$ & $\begin{array}{c}\text { Compulsive Tendencies (CT), } \\
\text { Control (C), Impaired } \\
\text { Communication/Self-Absorption } \\
\text { (IC/SA), Inability to Delegate (ID), } \\
\text { Self-Worth (SW) }\end{array}$ \\
\hline $\begin{array}{l}\text { Schaufeli, Shimazu \& Taris } \\
\text { (2009) }\end{array}$ & $\begin{array}{l}\text { Dutch Work Addiction } \\
\text { Scale (DUWAS) }\end{array}$ & $\begin{array}{l}\text { Working Excessively (WE), } \\
\text { Working Compulsively (WC) }\end{array}$ \\
\hline $\begin{array}{c}\text { Andreassen, Griffiths, } \\
\text { Hetland, \& Pallesen (2012) }\end{array}$ & $\begin{array}{l}\text { Bergen Work Addiction } \\
\text { Scale (BWAS) }\end{array}$ & None \\
\hline
\end{tabular}

Note: Content is obtained by collating relevant literature.

work Enjoyment has also been shown to be less relevant to workaholics [27]. 3) Although some workaholic scales are widely used, most of them lack a solid theoretical foundation, and the aggregation efficiency is not low [5] [14] [28]. 4) The current types of workaholic measurement tools are relatively simple, and the cross-scenario validity of existing scales needs further consideration and verification.

\section{Correlates of Workaholism}

After clarifying the definition and structure of the workaholic, it is necessary to explore the causes and consequences of Workaholism, so that we can understand the workaholic more deeply and provide some guidance for management practice. Literature studies show that the antecedents of workaholics can be divided into three levels: individual, organization and society.

\subsection{Individual Factors}

1) Demographic Characteristics. Literature studies have shown that demographic variables such as gender, age, parental social status, marital status, number of children, education, and marital status have an impact on workaholic behavior [11] [12] [29], Andreassen show basic demographic variables (age, gender, marriage, Status and education) explained $1.2 \%$ of difference in workaholics, and work-related statistical variables (employment status, position, department, annual income) can explain the difference of 5.4\% [30]. Among these variables, gender, parental social status, and workaholics are most closely related [31]. In general, when workaholics are driven by economic pressures (such as the economic pressures of caring for the family), marital status, parental social status, number of children, and workaholics are positively correlated. When workaholics are driven by other non-economic needs (such as self-esteem, guilt, etc.), these variables have little effect on workaholics [12]; And males are more likely to become workaholics [32], but some scholars have questioned that gender differences in previous studies may be differences in response to workaholic scale 
projects. In fact, women are more likely to become workaholics [29]; In addition, there is a positive correlation between education and long-term work [33].

2) Personality Traits. Personality traits have a long-lasting and stable effect on individual behavior, and many studies confirm the close relationship between workaholics and different personality traits. For example, type A personality is positively correlated with workaholics [34], Clark found that individuals with narcissistic have higher recognition of their importance and power needs, and are more likely to become workaholics [35]; the study of the relationship between self-esteem and workaholic is still controversial, Burke et al argue that individuals with high self-esteem have high expectations and high standards for themselves and too much work [36], while other scholars believe that low self-esteem individuals have low self-worth and often think that they have insufficient ability, This kind of cognition may drive low self-esteem people to work hard to achieve low success, so self-esteem and workaholics should be negative relevance [21] [37]. Aziz argued that the reason for the positive correlation with Burke may be that Bureke only measured one dimension of workaholics, namely work involvement [21]. The results of Clark et al. showed that self-esteem was not significantly related to workaholics [12]; Big Five personality is a comprehensive and effective personality classification method. Previous studies have shown that the five factors of Big Five personality are related to workaholics [25], as studied by Burke showed that extroversion was significantly positively correlated with work involvement and work enjoyment, neuroticism and work drive [36]. An empirical study by Clark et al showed a positive correlation between neuroticism and job drivers, and the other four factors were not found to be significantly associated with workaholics [35].

\subsection{Organizational Factors}

1) Work characteristics. The work characteristic variables are based on the Job Demands-Resources Model by Bakker and Demeroutican be divided into work requirements and work resources [38]. 1) Job requirements: There are three main job requirements that have an impact on the workaholic: a) role overloaded, that is, the employee thinks that they have a lot of work roles and the task does not have enough time to complete; b) role ambiguity, lack of job responsibilities for specific jobs Clear and clear definition; c) work conflict, employee ability and job role pressure do not match. Clark et al argued that there may be a positive correlation between these three jobs and the workaholics [12], but the conclusions need more empirical research support. 2) Working resources: The sense of work control and the support of superiors are two kinds of working resources that have an impact on workaholics. However, there are still few studies in this area. The current research mainly tests the relationship between work control, supervisor support, organizational support and other work resources and workaholics. Schaufeli, Bakker found that workaholics are less dependent on job control and supervisor support for these work resources, be- 
cause workaholics are more one-sided, stubborn, and self-sufficient [39]. Spurk found that organizational support increases employee psychological security and reduces employee workaholic levels [19]. But most studies show that work resources are negatively correlated with workaholics [12].

2) Organizational Culture. Organizational culture contains a set of core values, beliefs, shared meanings of potential ideologies, and basic assumptions that organizational life teaches new members the appropriate way of thinking [40]. Many studies have shown that organizational culture plays an important role in promoting and strengthening workaholics [9]. Workaholics are generally popular in the work environment of male culture characterized by extreme competition, eagerness for power, task orientation, and fear of failure [41]. Mazzetti empirical studies show that the excessive working atmosphere in the organization has a significant impact on the workaholic [41]. In addition, the competitive environment in the organization, especially the competition at the same level will promote the formation of workaholics [9] [42]. In addition, $\mathrm{Hu}$ explored the differences in workaholics in different cultural environments through surveys of five countries in the Netherlands, Spain, Finland, China, and Japan [43].

\subsection{Social Factors}

Not only do some internal factors within the organization affect workaholic behavior, but the external social environment also has an impact on workaholic behavior. With the changing labor market (such as global competition) many employees have to work harder [44], and the social competitive environment has prompted the expansion of the workaholic range. In addition, based on Bandura's social learning theory, individuals will be influenced by celebrities and some role models promoted by the media [28], if these socially influential celebrities or role models have workaholic behavior or tendencies, It can also lead to the possibility of individual workaholic behavior. The social support that employees receive also has an impact on workaholics, such as, Peplińska suggesting that social support can reduce women's workaholics [45]. Although the influence of social factors on workaholics cannot be ignored, some scholars have also discussed the influence of social factors on workaholics, but lack of in-depth empirical research, which is also a weak link that can be supplemented by future research.

In summary, these variables explain the generation and maintenance of workaholics from three different levels: individual, organization, and society. Workaholics may be caused by individual factors (such as demographic variables, personal traits), organizational factors (such as the characteristics of work, Organizational reward system) and the result of a combination of socio cultural factors (such as a culture that emphasizes competence and competition). However, at present, the research on the pre-worker's predisposition to variables is relatively simple and not comprehensive, and there is no unified view. The internal mechanism of the effects of various factors on the workaholics needs to be further explored. 


\section{Outcomes of Workaholism}

Is the impact of workaholics on organizational strategy and business operations positive or negative? What is the impact on the physical and mental health of the individual? This has always been a matter of great concern to businesses and individuals, and is a controversial issue in academia [46]. The current research on the workaholic outcome variables is concentrated at the individual level, which can be divided into three aspects: health, family and work.

\subsection{Health}

1) Physiological health. Meta-analysis by Clark shows that workaholics are negatively correlated with physical health [12]. Workaholics spend a lot of time and energy on their work, causing the brain and body to not get rest, rest and recovery [47]. Overwork will increase the activity of the sympathetic nervous system [48], and the coercive characteristics of workaholics can also cause anxiety, which can lead to increased heart rate and blood pressure [11], which leads to fatigue and sleep problems [49]. In addition, workaholics increase the probability of some diseases, for example, workaholics are an important risk factor for stress-related diseases and a major risk factor for cardiovascular disease [50] [51], Long-term work is an important risk factor for hypertension [52].

\subsection{Mental Health}

The key impact mechanism of workaholics on mental health may be the loss of energy and the loss of energy resources [11] [53]. Individuals often feel tired after a long period of work, and the workaholics continue to work and the resulting long-term fatigue can lead to various mental health problems unless the fatigue activity is stopped [2] [54] [55] [56]. This is because the individual's energy resources are limited. When the individual continues to invest in work-related activities, the resource pool may be occupied, and the loss of resources and insufficient energy recovery are important precursors to stress and fatigue [57].

\subsection{Family}

Family-related outcome variables include family satisfaction, marital satisfaction, interpersonal relationship satisfaction, and work-family conflicts. The excessive investment of workaholics in their work makes them have no time and energy to deal with interpersonal relationships, which can easily lead to low family satisfaction, low marital satisfaction, low interpersonal satisfaction, low family satisfaction, and work-family conflicts. Many empirical studies have shown that workaholics have a negative impact on interpersonal satisfaction [2] [58] [59], while workaholics sacrifice their family time and family responsibilities [18] leading to uncoordinated family relationships, family dysfunction, work-family conflicts [8] [21] [29], and so on. In recent years, the impact of workaholics on a person's family or other social roles has received increasing attention [12]. 


\subsection{Work}

1) Job performance. Workaholics have a controversial impact on job performance. On the one hand, workaholics have a positive effect on job performance. Workaholics invest more time and energy into their work, and their work will naturally be more productive and work better [50], Gorgievski' research suggests that workaholics are associated with entrepreneurial innovation behavior [60]. On the other hand, workaholics have an inhibitory effect on job performance [61]. The reasons are: First, workaholics need to work constantly and create more busy work, which makes simple work more complicated and therefore reduces job performance [3] [15]; then, The high workload may be related to lower job quality and productivity [16]; Finally, workaholics sacrifice interpersonal relationships because they are overworked, and may have an adverse effect on assessment.

2) Work pressure. Because workaholics are driven by internal pressures, and non-work is accompanied by negative emotions such as guilt and anxiety, So workaholics often set unreasonably high standards for themselves, so they may be subject to more work pressure [8] [21]. This has been supported by previous empirical studies. For example, Spence and Robbins found that workaholics were under greater pressure than those who really loved work. Kanai, Wakabayashi [16], and Fling also obtained the same research result. there may be a positive relationship between workaholics and work stress [62].

3) Job Satisfaction. The impact of workaholics on job satisfaction also be controversial. On the one hand, since workaholics often accompany negative emotions such as guilt when they are not working, they should have higher levels of satisfaction at work [13]. The study by Schaufeli supports this inference, and they find that workaholics are positively correlated with job satisfaction [18]. On the other hand, some scholars believe that the characteristics of workaholic high work drive, high work involvement and low work pleasure indicate to some extent that workaholics are not satisfied with the work [34] [61], this negative relationship can be explained by self-determination theory [63]: workaholics may be driven by the idea that the feels that they should work hard, not the individual's own values, the choice of goals and interests is free, so they may not feel real satisfaction at work [37].

From the above review, we can find that the impact of workaholics on personal health and family is mainly negative, and both positive and negative effects on work exist simultaneously. Therefore, the impact of workaholics on work cannot be viewed simply from the negative and positive dimensions, and may need to be explored from a more macro perspective. For example, we can analyze the impact of workaholics on work from a short-term and long-term perspective. From the short-term results, workaholics invest a lot of time and energy at work, and job performance may be higher than non-workaholics. But in the long run, workaholics can lead to more physical and mental health problems, poor interpersonal relationships, and discordant family life, which may reduce job effec- 
tiveness [12]. In addition, the current workaholic outcome variables are limited to the individual level, and few studies aggregate the workaholic outcome variables into organizational or team level exploration. Future research may require an integrated framework to explain the impact of workaholics on the organization, and explore the areas in which workaholics can improve job performance and promote overall organizational development. Under what circumstances workaholics will reduce job performance, damage organizational interests, and hinder organizational development.

\section{Interventions of Workaholism}

Although the research on the characteristics and influencing factors of workaholics has not yet reached a complete agreement, scholars mostly agree that workaholics have some negative effects on individuals, their families and organizations. Based on the previous summary of the workaholic precautionary variables, the workaholic intervention strategy should consider the internal factors such as individual personality traits, behavioral motivation, value cognition, etc., as well as the external environment in which the individual is located, such as family education and organization culture. Therefore, workaholic intervention requires the cooperation of organizations, families, and individuals and based on the literature research, this paper constructs a multi-level, all-round intervention system with multiple approaches and internal and external considerations.

First level, prevention mechanism. Organizational culture and the family environment are important causes of workaholics [24] [41]. In the organization, the norms and values that match reasonable work involvement and focus on efficiency can be established. Specifically, companies can take the following measures: First, establish a balance between efforts and rewards. If a scientific incentive system is set up, avoid the phenomenon of workaholics by means of praise or material rewards; second, reasonable scheduling of work tasks. Organizations can assign appropriate stimulating and challenging tasks to employees; third, giving employees continuity and constructiveness feedback. Understand the work dynamics of employees and guide them to improve work efficiency. Fourth, give employees a bright future and security from the perspective of employees. In the family environment, we can prevent workaholics from the following two aspects. First, to ensure normal family system functions, to create a good family growth environment. Second, set the right example in the family, parents and other family members try not to behave as a workaholic [64]. In addition, avoiding excessively harsh or beloved parenting styles can reduce the probability of workaholics.

Second level, control mechanism. This stage is mainly to improve the management and control ability of the employees in the face of workaholic risk through selection and training. According to the trait theory, personality traits have a significant predictive effect on workaholics, enterprises can control both in terms of selection and training. First, enterprises can avoid such characteristic 
people in the selection process, or select suitable positions for them to avoid high pressure, high competition or excessive work environment; Second, the organization can arrange employee training on work-life balance, such as time management, decompression and relaxation techniques, and setting boundaries (Andreassen et al., 2014), flexible work hours can also reduce work-family Conflict (Russo \& Waters, 2006).

The third level, intervention mechanism. For workaholic members in the organization, it is necessary to take a comprehensive intervention on their motivation, cognition, and behavior to minimize the harm of workaholics. The organization can provide internal or external consultants to employees, and can also help workaholics get out of trouble through various professional psychological counseling and treatment methods. Among the corresponding interventions, motivational talks (MI) and cognitive behavioral therapy (CBT) are often used to treat behavioral addiction and are an effective way to treat workaholics.

In general, research on workaholic interventions is currently very limited, and existing treatments are based primarily on theoretical recommendations or inconclusive clinical reports (Gordon et al., 2017). The negative impact on individuals and organizations has been supported by a large body of research and cannot be underestimated (Aziz et al., 2018; Shkoler et al., 2017; Gillet et al., 2017), so future research needs to be explored in this area, this is also the significance of research workaholic practice.

\section{Future Research Directions}

This paper systematically sorts out the concept of workaholics, the research on workaholics has made certain progress. At the same time, there are still some problems in the existing research. Future research needs to be further expanded and improved in the research content and methods.

First, clarify the conceptual connotation of workaholics. At present, the divergence of workaholic concepts has seriously hampered the development of workaholic theory and empirical research (Clark et al., 2016). Therefore, clarifying the connotation and extension of workaholics is the premise basis for further empirical research. Summarizing the existing research, the controversy of the workaholic concept is mainly concentrated on two points: the degree of compulsion to the work and experience's emotional experience. To clarify whether workaholics really enjoy work is an important key to distinguish between workaholics and work commitments, and to clarify the degree of compulsion of workaholics to work can clarify the difference between workaholics and general material addiction behavior. Although these two points have been discussed in the past literature, they lack theoretical basis and empirical evidence, and further research is needed.

Second, improve the measurement tools of workaholics. The development and improvement of measurement tools is an important guarantee for promoting the empirical research of workaholics. At present, the research on the workaholic 
structure is still under investigation, the content and elements of the workaholic are still uncertain and controversial. Most of the developed workaholic scales lack a solid theoretical foundation, and the aggregation efficiency between them is not high [5]. Future research needs to further explore the concept and composition of workaholics, further development and Improve the measurement tools of workaholics. In addition, future researchers need to develop a local workaholic scale based on the original concept of the West, combined with domestic organizational situations and management practices, to further promote the development of workaholic research in China.

Third, expand the impact mechanism of workaholics. The existing research mainly discusses the formation of workaholics from the perspectives of organizational environment and individual personality traits, but less attention is paid to psychological factors such as individual emotional intelligence and psychological resilience. Future research can explore the impact of factors such as psychological security, work safety, and psychological capital on workaholics. Second, the formation of workaholics is the result of social, organizational, and individual interactions. The current research focuses on one. At the level, there is a lack of a comprehensive discussion of the influence mechanism of workaholics from the perspective of individuals and organizations. Therefore, cross-level research of workaholics is an important breakthrough in future research.

Fourth, improve the intervention system of workaholics. Extensive empirical research have shown that workaholics have a negative impact on both organizations and individuals. Is there a way to avoid workaholics and slow down the negative effects of workaholics? In the past, there was little research on the intervention of workaholics. Although this paper has compiled a complete and comprehensive intervention system based on the predecessors, the future research needs to be continuously improved and improved. Through the continuous interaction between practice and theoretical research, the practical value of workaholic research.

Fifth, Combine diverse research methods. Most of the existing researches use questionnaires to measure workaholics. These measurement tools are mainly self-assessed by the respondents and there are homologous method biases. Future research can be measured in combination with self-assessment and other evaluation methods. It can also be measured in different time periods; in addition, longitudinal research will help the workaholic research to be deeper. The use of tracking surveys can help us to understand the development process of workaholics and dynamically examine the effects and changes of workaholics on employees and organizations.

\section{Conclusion}

This study reviews the development of workaholics. Although workaholic research has developed slowly, more and more scholars have begun to pay attention to this topic in recent years. In fact, although workaholics are more com- 
mon in daily work, the existing academic research is still very limited. Understanding the correlates and outcomes of workaholics can provide a theoretical basis for the management of enterprises, but the relevant research is still very limited. We hope that future research can conduct empirical research on the basis of clarifying the nature of workaholics, which is currently particularly needed.

\section{Conflicts of Interest}

The author declares no conflicts of interest regarding the publication of this paper.

\section{References}

[1] Oates, W.E. (1971) Confessions of a Workaholic: The Facts about Work Addiction. World Publishing Company.

[2] Shkoler, O., Rabenu, E., Vasiliu, C., Sharoni, G. and Tziner, A. (2017) Organizing the Confusion Surrounding Workaholism: New Structure, Measure, and Validation. Frontiers in Psychology, 8, 1803. https://doi.org/10.3389/fpsyg.2017.01803

[3] Scottl, K.S., Moore, K.S. and Miceli, M.P. (1997) An Exploration of the Meaning and Consequences of Workaholism. Human Relations, 50, 287-314. https://doi.org/10.1177/001872679705000304

[4] Mosier, S.K. (1983) Workaholics: An Analysis of Their Stress, Success and Priorities. University of Texas, Austin.

[5] Andreassen, C.S., Griffiths, M.D., Hetland, J., Kravina, L., Jensen, F. and Pallesen, S. (2014) The Prevalence of Workaholism: A Survey Study in a Nationally Representative Sample of Norwegian Employees. PLoS One, 9, e102446.

https://doi.org/10.1371/journal.pone.0102446

[6] Villella, C., Martinotti, G., Di Nicola, M., Cassano, M., La Torre, G., Gliubizzi, M.D., Conte, G., et al. (2011) Behavioural Addictions in Adolescents and Young Adults: Results from a Prevalence Study. Journal of Gambling Studies, 27, 203-214. https://doi.org/10.1007/s10899-010-9206-0

[7] Sussman, S., Lisha, N. and Griffiths, M. (2011) Prevalence of the Addictions: A Problem of the Majority or the Minority? Evaluation \& the Health Professions, 34, 3-56. https://doi.org/10.1177/0163278710380124

[8] Van Gordon, W., Shonin, E., Dunn, T.J., Garcia-Campayo, J., Demarzo, M.M., and Griffiths, M.D. (2017) Meditation Awareness Training for the Treatment of Workaholism: A Controlled Trial. Journal of Behavioral Addictions, 6, 212-220. https://doi.org/10.1556/2006.6.2017.021

[9] Keller, A.C., Spurk, D., Baumeler, F. and Hirschi, A. (2016) Competitive Climate and Workaholism: Negative Sides of Future Orientation and Calling. Personality and Individual Differences, 96, 122-126. https://doi.org/10.1016/j.paid.2016.02.061

[10] Quinones, C., Griffiths, M.D. and Kakabadse, N.K. (2016) Compulsive Internet Use and Workaholism: An Exploratory Two-Wave Longitudinal Study. Computers in Human Behavior, 60, 492-499. https://doi.org/10.1016/j.chb.2016.02.060

[11] Balducci, C., Avanzi, L. and Fraccaroli, F. (2016) The Individual "Costs" of Workaholism: An Analysis Based on Multisource and Prospective Data. Journal of Management, 0149206316658348.

[12] Clark, M.A., Michel, J.S., Zhdanova, L., Pui, S.Y. and Baltes, B.B. (2016) All Work and No Play? A Meta-Analytic Examination of the Correlates and Outcomes of 
Workaholism. Journal of Management, 42, 1836-1873. https://doi.org/10.1177/0149206314522301

[13] Ng, T.W., Sorensen, K.L. and Feldman, D.C. (2007) Dimensions, Antecedents, and Consequences of Workaholism: A Conceptual Integration and Extension. Journal of Organizational Behavior, 28, 111-136. https://doi.org/10.1002/job.424

[14] Loscalzo, Y. and Giannini, M. (2017) Clinical Conceptualization of Workaholism: A Comprehensive Model. Organizational Psychology Review, 7, 306-329. https://doi.org/10.1177/2041386617734299

[15] Fassel, D. (1990) Working Ourselves to Death: The High Cost of Workaholism, the Rewards of Recovery. Harper San Francisco.

[16] Spence, J.T. and Robbins, A.S. (1992) Workaholism: Definition, Measurement, and Preliminary Results. Journal of Personality Assessment, 58, 160-178. https://doi.org/10.1207/s15327752jpa5801_15

[17] Sussman, S. (2012) Workaholism: A Review. Journal of Addiction Research \& Therapy, 6, 4120-4138. https://doi.org/10.4172/2155-6105.S6-001

[18] Schaufeli, W.B., Taris, T.W. and Van Rhenen, W. (2008) Workaholism, Burnout, and Work Engagement: Three of a Kind or Three Different Kinds of Employee Well-Being? Applied Psychology, 57, 173-203. https://doi.org/10.1111/j.1464-0597.2007.00285.x

[19] Spurk, D., Hirschi, A. and Kauffeld, S. (2016) A New Perspective on the Etiology of Workaholism: The Role of Personal and Contextual Career-Related Antecedents. Journal of Career Assessment, 24, 747-764. https://doi.org/10.1177/1069072715616127

[20] Bonebright, C.A., Clay, D.L. and Ankenmann, R.D. (2000) The Relationship of Workaholism with Work-Life Conflict, Life Satisfaction, and Purpose in Life. Journal of Counseling Psychology, 47, 469-477. https://doi.org/10.1037/0022-0167.47.4.469

[21] Aziz, S., Zamary, S. and Wuensch, K. (2018) The Endless Pursuit for Self-Validation through Attainment: An Examination of Self-Esteem in Relation to Workaholism. Personality and Individual Differences, 121, 74-79. https://doi.org/10.1016/j.paid.2017.09.024

[22] Baruch, Y. (2011) The Positive Wellbeing Aspects of Workaholism in Cross Cultural Perspective: The Chocoholism Metaphor. Career Development International, 16, 572-591. https://doi.org/10.1108/13620431111178335

[23] Mudrack, P.E. and Naughton, T.J. (2001) The Assessment of Workaholism as Behavioral Tendencies: Scale Development and Preliminary Empirical Testing. International Journal of Stress Management, 8, 93-111. https://doi.org/10.1023/A:1009525213213

[24] Andreassen, C.S., Griffiths, M.D., Hetland, J. and Pallesen, S. (2012) Development of a Work Addiction Scale. Scandinavian Journal of Psychology, 53, 265-272. https://doi.org/10.1111/j.1467-9450.2012.00947.x

[25] Jackson, S.S., Fung, M.C., Moore, M.A.C. and Jackson, C.J. (2016) Personality and Workaholism. Personality and Individual Differences, 95, 114-120. https://doi.org/10.1016/j.paid.2016.02.020

[26] McMillan, L.H., Brady, E.C., O’Driscoll, M.P. and Marsh, N.V. (2002) A Multifaceted Validation Study of Spence and Robbins' (1992) Workaholism Battery. Journal of Occupational and Organizational Psychology, 75, 357-368. https://doi.org/10.1348/096317902320369758

[27] Mudrack, P.E. (2006) Understanding Workaholism: The Case for Behavioral Ten- 
dencies. Research Companion to Working Time and Work Addiction (Edward Elgar). https://doi.org/10.4337/9781847202833.00013

[28] Andreassen, C.S., Hetland, J. and Pallesen, S. (2013) Psychometric Assessment of Workaholism Measures. Journal of Managerial Psychology, 29, 7-24. https://doi.org/10.1108/JMP-05-2013-0143

[29] Beiler-May, A., Williamson, R.L., Clark, M.A. and Carter, N.T. (2017) Gender Bias in the Measurement of Workaholism. Journal of Personality Assessment, 99, 104-110. https://doi.org/10.1080/00223891.2016.1198795

[30] Andreassen, C.S., Griffiths, M.D., Sinha, R., Hetland, J. and Pallesen, S. (2016) The Relationships between Workaholism and Symptoms of Psychiatric Disorders: A Large-Scale Cross-Sectional Study. PLoS ONE, 11, e0152978. https://doi.org/10.1371/journal.pone.0152978

[31] Snir, R. and Harpaz, I. (2012) Beyond Workaholism: Towards a General Model of Heavy Work Investment. Human Resource Management Review, 22, 232-243. https://doi.org/10.1016/j.hrmr.2011.11.011

[32] Snir, R. and Harpaz, I. (2006) The Workaholism Phenomenon: A Cross-National Perspective. Career Development International, 11, 374-393. https://doi.org/10.1108/13620430610683034

[33] Ng, T.W. and Feldman, D.C. (2008) Long Work Hours: A Social Identity Perspective on Meta-Analysis Data. Journal of Organizational Behavior, 29, 853-880. https://doi.org/10.1002/job.536

[34] Rezvani, A., Bouju, G., Keriven-Dessomme, B., Moret, L. and Grall-Bronnec, M. (2014) Workaholism: Are Physicians at Risk? Occupational Medicine, 64, 410-416. https://doi.org/10.1093/occmed/kqu081

[35] Clark, M.A., Lelchook, A.M. and Taylor, M.L. (2010) Beyond the Big Five: How Narcissism, Perfectionism, and Dispositional Affect Relate to Workaholism. Personality and Individual Differences, 48, 786-791. https://doi.org/10.1016/j.paid.2010.01.013

[36] Burke, R.J., Matthiesen, S.B. and Pallesen, S. (2006) Personality Correlates of Workaholism. Personality and Individual Differences, 40, 1223-1233. https://doi.org/10.1016/j.paid.2005.10.017

[37] Graves, L.M., Ruderman, M.N., Ohlott, P.J. and Weber, T.J. (2012) Driven to Work and Enjoyment of Work: Effects on Managers' Outcomes. Journal of Management, 38, 1655-1680. https://doi.org/10.1177/0149206310363612

[38] Bakker, A.B. and Demerouti, E. (2007) The Job Demands-Resources Model: State of the Art. Journal of Managerial Psychology, 22, 309-328. https://doi.org/10.1108/02683940710733115

[39] Schaufeli, W.B., Bakker, A.B., van der Heijden, F.M. and Prins, J.T. (2009) Workaholism among Medical Residents: It Is the Combination of Working Excessively and Compulsively That Counts. International Journal of Stress Management, 16, 249-272. https://doi.org/10.1037/a0017537

[40] Schein, E.H. (2010) Organizational Culture and Leadership. Vol. 2, John Wiley \& Sons, Hoboken.

[41] Mazzetti, G., Schaufeli, W.B. and Guglielmi, D. (2014) Are Workaholics Born or Made? Relations of Workaholism with Person Characteristics and Overwork Climate. International Journal of Stress Management, 21, 227-254. https://doi.org/10.1037/a0035700

[42] Morkevičiūtè, M. and Endriulaitienè, A. (2017) The Relationship between a Perceived Ethical Leadership Style and Workaholism. International Conference on 
Business and Economics, Birmingham, 27-29 October 2017, Vol. 1, 130-140. https://doi.org/10.15405/epms.2017.06.13

[43] Hu, Q., Schaufeli, W., Taris, T.W., Hessen, D.J., Hakanen, J., Salanova, M. and Shimazu, A. (2014) East Is East and West Is West and Never the Twain Shall Meet. Work Engagement and Workaholism across Eastern and Western Cultures. Journal of Behavioral and Behavioral Sciences, 1, 6-24.

[44] Van Beek, I., Hu, Q., Schaufeli, W.B., Taris, T.W. and Schreurs, B.H. (2012) For Fun, Love, or Money: What Drives Workaholic, Engaged, and Burned-Out Employees at Work? Applied Psychology, 61, 30-55. https://doi.org/10.1111/j.1464-0597.2011.00454.x

[45] Peplińska, A., Wojdylo, K., Kosakowska-Berezecka, N. and Połomski, P. (2015) The Role of Purpose in Life and Social Support in Reducing the Risk of Workaholism among Women in Poland. Health Psychology Report, 3, 326-335.

https://doi.org/10.5114/hpr.2015.50902

[46] Clark, M.A., Michel, J.S., Stevens, G.W., Howell, J.W. and Scruggs, R.S. (2014) Workaholism, Work Engagement and Work-Home Outcomes: Exploring the Mediating Role of Positive and Negative Emotions. Stress and Health, 30, 287-300. https://doi.org/10.1002/smi.2511

[47] Schulz, A.S., Bloom, J. and Kinnunen, U. (2017) Workaholism and Daily Energy Management at Work: Associations with Self-Reported Health and Emotional Exhaustion. Industrial Health, 55, 252-264. https://doi.org/10.2486/indhealth.2016-0150

[48] Landsbergis, P. (2004) Long Work Hours, Hypertension, and Cardiovascular Disease. Cadernos de Saude Publica, 20, 1746-1748. https://doi.org/10.1590/S0102-311X2004000600035

[49] Kubota, K., Shimazu, A., Kawakami, N. and Takahashi, M. (2014) Workaholism and Sleep Quality among Japanese Employees: A Prospective Cohort Study. International Journal of Behavioral Medicine, 21, 66-76. https://doi.org/10.1007/s12529-012-9286-6

[50] Salanova, M., López-González, A.A., Llorens, S., Del Líbano, M., Vicente-Herrero, M.T. and Tomás-Salvá, M. (2016) Your Work May Be Killing You! Workaholism, Sleep Problems and Cardiovascular Risk. Work \& Stress, 30, 228-242. https://doi.org/10.1080/02678373.2016.1203373

[51] Aziz, S., Wuensch, K.L. and Duffrin, C. (2015) Workaholism, Exercise, and Stress-Related Illness. Journal of Workplace Behavioral Health, 30, 393-406. https://doi.org/10.1080/15555240.2015.1074053

[52] Yang, H., Schnall, P.L., Jauregui, M., Su, T.C. and Baker, D. (2006) Work Hours and Self-Reported Hypertension among Working People in California. Hypertension, 48, 744-750. https://doi.org/10.1161/01.HYP.0000238327.41911.52

[53] Shirom, A. (2003) Job-Related Burnout: A Review. In: Quick, J.C. and Tetrick, L.E., Eds., Handbook of Occupational Health Psychology, American Psychological Association, Washington DC, 245-264. https://doi.org/10.1037/10474-012

[54] Gillet, N., Morin, A.J., Cougot, B. and Gagné, M. (2017) Workaholism Profiles: Associations with Determinants, Correlates, and Outcomes. Journal of Occupational and Organizational Psychology, 90, 559-586. https://doi.org/10.1111/joop.12185

[55] Midje, H.H., Nafstad, I.T., Syse, J. and Torp, S. (2014) Workaholism and Mental Health Problems among Municipal Middle Managers in Norway. Journal of Occupational and Environmental Medicine, 56, 1042-1051. https://doi.org/10.1097/JOM.0000000000000223 
[56] Bakker, A.B., Demerouti, E., Oerlemans, W. and Sonnentag, S. (2013) Workaholism and Daily Recovery: A Day Reconstruction Study of Leisure Activities. Journal of Organizational Behavior, 34, 87-107. https://doi.org/10.1002/job.1796

[57] Hobfoll, S.E. (2011) Conservation of Resource Caravans and Engaged Settings. Journal of Occupational and Organizational Psychology, 84, 116-122. https://doi.org/10.1111/j.2044-8325.2010.02016.x

[58] Levy, D.V. (2015) Workaholism and Marital Satisfaction among Female Professionals. The Family Journal, 23, 330-335. https://doi.org/10.1177/1066480715601109

[59] Bakker, A.B., Demerouti, E. and Burke, R. (2009) Workaholism and Relationship Quality: A Spillover-Crossover Perspective. Journal of Occupational Health Psychology, 14, 23-33. https://doi.org/10.1037/a0013290

[60] Gorgievski, M.J., Antonio Moriano, J. and Bakker, A. (2014) Relating Work Engagement and Workaholism to Entrepreneurial Performance. Journal of Managerial Psychology, 29, 106-121. https://doi.org/10.1108/JMP-06-2012-0169

[61] Serrano-Fernández, M.J., Boada-Grau, J., Gil-Ripoll, C. and Vigil-Colet, A. (2016) A Predictive Study of Antecedent Variables of Workaholism. Psicothema, 28, 401-406.

[62] Kanai, A., Wakabayashi, M. and Fling, S. (1996) Workaholism among Employees in Japanese Corporations: An Examination Based on the Japanese Version of the Workaholism Scales. Japanese Psychological Research, 38, 192-203. https://doi.org/10.1111/j.1468-5884.1996.tb00024.x

[63] Gagné, M. and Deci, E.L. (2005) Self-Determination Theory and Work Motivation. Journal of Organizational Behavior, 26, 331-362. https://doi.org/10.1002/job.322

[64] Kravina, L., Falco, A., De Carlo, N.A., Andreassen, C.S. and Pallesen, S. (2014) Workaholism and Work Engagement in the Family: The Relationship between Parents and Children as a Risk Factor. European Journal of Work and Organizational Psychology, 23, 875-883. https://doi.org/10.1080/1359432X.2013.832208 